\title{
Efficient implementation of high technologies in educational process
}

\author{
Ekaterina N. Yadova ${ }^{1, *}$, Gregory Bubnov ${ }^{1}$ and Evgeniy Pluzhnik ${ }^{1}$ \\ ${ }^{1}$ Moscow Technological Institute, 199334, Moscow, Russia
}

\begin{abstract}
The paper describes the aspects of the augmented reality application development on the base of ARToolkit for Android. The steps consistently used for the augmented reality application development have been considered. The simplest Java-based examples of augmented reality have been discussed.
\end{abstract}

\section{Introduction}

The global development unavoidably includes extreme grows of high technologies. Therefore many spheres of business and sciences are forced to evaluate to make provision for transforming social needs. One of the important field, where high technologies are seriously necessary and exceptionally sought-after is education.

To keep the professional level it is critical to study from time to time. And longlife learning gives great competitive advantage. The big data and global knowledge are so huge, that is impossible to get them all. And therefore on the front burner came content quality and its generalization. Every operation with information must be pending on maximum time and cost saving simultaneously with succeeding high coefficient of efficiency.

At the present time increased demand for distant learning, online courses, coaching, mentoring rapidly grow.

To expand the list of modern developments in education we can mention such technologies as learning with instruments of virtual reality [1], brain-computer interface [2] and physiological data (like electroencephalography, electrocardiogram etc.) tracking [3].

Virtual reality makes the participant in course [4] fully dip into the learning process and pay no regard for ambient noisedistractions. Such actions increase the effectiveness of gaining knowledge. Virtual reality technologies most accurately for creating and using in learning process for creating educational simulators which improving skills.

BCI (brain-computer interface) is one more opportunity for increasing the quality of material retention. The highest use of this technology is in medicine now. But operating a computer without using hands affords education ground for increasing numbers of sense modality for knowledge acquiring and reacting on a new content in prospect.
Physiological data tracking is one more technological opportunity for the learning content and optimization, needed for deep information perceiving. Physiological non-verbal reaction on the educational material could help to organize the content in optimal for percepting way. Tracking such information is already ordinary for sport, including amateur one. Using physiological values can help to shorten time for reaching learning result of that process, for example, the trainees start getting knowledge in optimal physically and psychological fit.

Using mentioned technologies stimulates creating new informational trends and strong interest for the educational values. Consequently, new technologies could be implemented in a learning process.

Examples of successful using of new technologies in education have existed for more than 15 years [5]. New effective practices come into ordinary life every day [6]. But such technologies have to become part of ordinary life.

Difficulties of high technologies implementation into education are the same as in change management any sphere. Troubles exist, but they are overcomable and eventual. Teachers, lectors, managers of learning process would be forced by reality to evaluate with high technologies, and they appraise the convenience and opportunities at long last.

New technological reality inspires to search and analyse needed changes in educational management and content. Understanding how participants of educational courses of process percept technologies is necessary for planning and realization changes.

So we are aimed at the research of implementing in and apperception of high technologies in education.

New technological decisions make possible extremely powering up of the learning process, improvement of the effectiveness of receiving knowledge and raising satisfaction of all processparticipants. 


\section{Material and Methods}

Classical Roger's model testifies the new technologies are aimed to use by only 2,5\% innovators [7]. After innovators get involved early adopters $-13,5 \%$. And for now Roger's model is useful but in transformational and more detailed way. For instance, in 2013 [4] it was indicated that $60 \%$ of K-5 primary school teachers adopted GBL, which was in Rogers' late majority stage, whereas only $25 \%$ of the 6-12 secondary school teachers adopted GBL, which was in Rogers' early majority stage [8] S. C. S. Li and W. C Huang studying teachers' adoption of game-based learning (GBL) detected that lifestyles and perceived attributes of respondents influenced a strong outcome, whereas demographics factor in innovation actions had only a moderate result in discriminating the non-adopters from the early adopters, adopters and likely adopters.

Every model is transforming through years. And it is necessary to indicate actual situation.

Embracing some processes and events needs to be stimulated, because participants might be unprepared to the reality.

People are forced to percept technologies because of its exclusionary development and implementation in daily live [9]. While academic world decides what definition is more acceptably [10], common person meets technology in real life.

By introducing new thinking to people with, let's say, advanced lifestyles, probable, it's easier to get active implementations of innovations in such groups. In consequence such groups will stimulate easier expansion of innovations on a wide range of customers.

To test such an idea a survey was done involving 219 students of MBA programs, enrolled in the system of distant learning - Learning Management System (LMS). The fact of studying in LMS testifies the readiness of using high technologies in educational process, that is Internet network for receiving knowledge and controlling results. So it is a sort of indicator of lifestyle. The results are set out in descriptive statistic because of clarity and one-valuedness of such way.

\section{Results}

To describe lifestyle of the targeted audience information about their goals and characteristics of learning process. Results are presented with a linear distribution.

Table 1. Frequency of answers on a question «What did you expect from the educational program at the beginning of studying»? Reckoning might be over $100 \%$ because of respondents ability of giving any response numbers.

\begin{tabular}{|c|c|}
\hline & $\begin{array}{c}\text { \% of the total } \\
\text { number }\end{array}$ \\
\hline Acquiring of new knowledge & 90 \\
\hline Current knowledge systematization & 70 \\
\hline Career development & 64 \\
\hline Increasing of income & 43 \\
\hline Opening of a business / project & 32 \\
\hline
\end{tabular}

\begin{tabular}{|c|c|}
\hline Actual problem solving & 25 \\
\hline Networking & 24 \\
\hline Changing the professional sphere & 23 \\
\hline
\end{tabular}

According to the results shown in Table 1 overwhelming majority of the targeted audience expected acquiring of new knowledge (90\%) and of Current knowledge systematization (70\%).

Table 2. Frequency of answers on a question «What the most important advantage of learning in educational facility for you?». Reckoning might be over $100 \%$ because of respondents ability of giving any response numbers

\begin{tabular}{|c|c|}
\hline Learning like on-the-job & $\begin{array}{c}\text { \% of the total } \\
\text { number }\end{array}$ \\
\hline Tutoring & 91 \\
\hline Structured information receiving & 54 \\
\hline Price & 51 \\
\hline Practice-oriented learning & 49 \\
\hline $\begin{array}{c}\text { Receiving content in video files in } \\
\text { addition to text }\end{array}$ & 39 \\
\hline Practical experiensed tutors & 38 \\
\hline High technologies & 35 \\
\hline
\end{tabular}

High technologies in education are highly appreciated by $35 \%$ respondents of group of interest. It might be a proxy data for openness to innovations (Table 2).

Table 3. Frequency of answers on a question «What computing system and gadget do you use ...?» Reckoning might be over $100 \%$ because of respondents ability of giving any response numbers

\begin{tabular}{|c|c|c|}
\hline & $\begin{array}{c}\text { In your } \\
\text { ordinary daily } \\
\text { and } \\
\text { professional } \\
\text { life, \% of the } \\
\text { total number }\end{array}$ & $\begin{array}{c}\text { In LMS, \% } \\
\text { of the total } \\
\text { number }\end{array}$ \\
\hline Laptop «non-Apple» & 62 & 58 \\
\hline PC «non-Apple» & 50 & 38 \\
\hline Tablet Apple & 42 & 30 \\
\hline Smartphone on Android & 42 & 13 \\
\hline iPhone & 38 & 11 \\
\hline Tablet on Android & 32 & 20 \\
\hline Laptop Apple & 18 & 14 \\
\hline PC Apple & 9 & 5 \\
\hline
\end{tabular}

The results above showactive involvement of the group targeted into the modern technological life (Table $3)$.

Table 4. Frequency of answers on a question «What financial resources did you use to pay for education?». Respondent could give one answer

\begin{tabular}{|c|c|}
\hline & $\begin{array}{c}\text { \% of the total } \\
\text { number }\end{array}$ \\
\hline I financed myself & 74 \\
\hline Raised employer's funds & 11 \\
\hline Bank credit & 8 \\
\hline Borrowed from relatives & 4 \\
\hline Employers credit & 3 \\
\hline
\end{tabular}


In addition to the description of the audience (Table $1-4)$. It was defined that $74 \%$ used self finance to pay the cost, $11 \%$ raised funds. The majority $(76 \%)$ are full timeemploees, $11 \%$ - are in job search, $7 \%$ - emploees have no fixed office hours or worke part time, $4 \%$ - are on maternity leave.

Results mentioned on Figure 1 makes suggest that audience is rather ambitious.

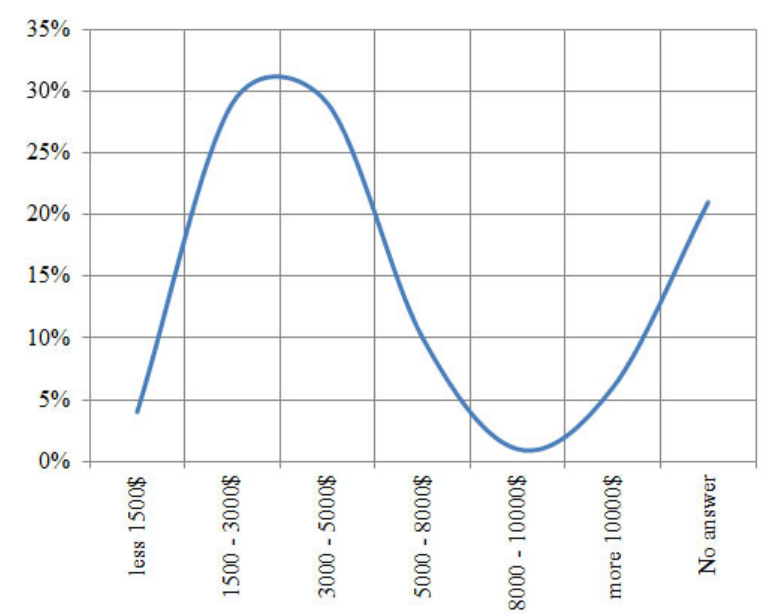

Fig. 1. Frequency of answers on a question «What earnings per month do you plan to have after graduating? ». Respondent could give one answer

Half of the participants (48\%) said than they were enrolled in educational programs except current one. This number might show that every second respondent's realises longlife learning.

Demographical characteristics of the audience: women $-46 \%$, men $-54 \%$, higher education in one sphere has $75 \%$, higher education in two or more spheres has $23 \%, 75 \%$ respondents are married, $25 \%$ - are not.

Table 5. Frequency of answers on a question «Please, select more proper declaration». Respondent could give one answer

\begin{tabular}{|c|c|}
\hline $\begin{array}{c}\text { In education it is necessary to } \\
\text { practice extremely high technologies } \\
\text { such as brain-signals pickup and } \\
\text { fatigability online tracking }\end{array}$ & $\begin{array}{c}\text { \% of the total } \\
\text { number }\end{array}$ \\
\hline $\begin{array}{c}\text { It would be better to make education } \\
\text { in traditional, classical way, not to } \\
\text { divert from the content by unusual } \\
\text { forms }\end{array}$ & 56 \\
\hline
\end{tabular}

More than third of respondents (44\%) choose the answer, more oriented on innovations, high technologies (Table 5).

\section{Discussion}

The majority of respondents $(56 \%)$, preferred education in traditional, classical way, without diverting from the content by unusual forms.

But the other $44 \%$ told that in education it is necessary to practice extremely high technologies such as brain-signals pickup and fatigability online tracking. It is a significant variation, which may content persons from innovators group, early adopters and event part of early majority (by Roger's model).

However mentioned technologies are not used in education widely now. Therefore the group of those who choose the declaration with extremely high technologies includes innovators, but in larger number.

Such results could be determined by every daily using technologies - 1ms, which demonstrate a sort of the indicator of lifestyle-preparedness.

Attained results show that an audience of active lmsusers, who study one or more educational programs presents high readiness to accept high technologies, like brain-signals pickup and fatigability online fatigability tracking.

Consideration must be given to the circumstance that the output are not representative for the concrete sampled population because of the characteristics of representative sample. The results could be used for creating more hypothesis for next surveys.

The introduced results allow to suppose that some lifestyle's characteristics which can facilitate easy acceptance of educational innovations exist. For example, it could include active use of distant learning technologies, frequent attendance of online conferences, active use of online payment and so on. Probably, technology loyalty, created by all past experience will stimulate positive perception of new technologies in educational process.

Such involvement «step-by-step» will bring real high technologies into a daily and professional life for more and more people.

\section{Conclusion}

Output can be practically used even now. Almost every second respondent from the audience who study in the lms does not exclude the necessity of high technologies implementation. And it is with the assumption that brainsignals pickup and fatigability online tracking are not well known for a wide audience. But the characteristics of lifestyles allows to implement the information about such methods, and afterwards - the methods itself.

High technologies are to raise the education effectiveness even with a decreased time commitment. Measuring the physiological status allows to select the most appropriate moment for studying, like already do with sleep phase for wake-up.

One more opportunity for using high technologies is possible. But here is the clause that recipient takes some kind of profits and does not demur to practice. Brainsignals pickup and fatigability online tracking could help to control lessons learned. It is not actually about honesty at the tests. Higher value of fixing, for example, real stress-level and gaining efficiency purposefully. Or it could be selection of the best time for testing resting upon the physiological measures.

Involvement of high technologies in education opens the door to multiple opportunities for perfection the process and results of learning. And it is extremely 
necessary for accelerating global technology world, technological evolution of daily living and availability requirements.

New high technologies (including neuro-, virtual reality and another measures) can create the impressive contributions to education, even if it wouldn't be by guiding the work of teachers [11].

Education must help and stimulate getting new knowledge, improving skills, becoming integrated in new situation, extensively and dynamically act in unexpected developments and keeping pace with real practice and life.

\section{References}

1. B. Yilmaz, M. Goken, Global Journal on Humanites \& Social Sciences, 03, 498-503 (2016) Available from: http://sproc.org/ojs/index.php/pntsbs

2. B.F. Yuksel, K.B. Oleson, L. Harrison, E.M. Peck, D. Afergan, R. Chang, R. J. Jacob, In Proceedings of the 2016 CHI Conference on Human Factors in Computing Systems, p. $5372-5384$ (2016)
3. R. Azevedo et al. Methodological Advances in Research on Emotion and Education, p. 231-243 (2016)

4. M.D. Proctor, Y. Marks, Computers \& Education, 62, 171-180 (2013)

5. A. Von Baeyer, H. Sommer, Educational Conditions for Successful Training with Virtual Reality Technologies Human Performance Goals Workshop (Netherlands, 2000)

6. J. Manuel, A. Goodwyn, D. Zancanella, English Teaching: Practice \& Critique, 15 (2016)

7. E. M. Rogers, G. M. Beal, The. Soc. F., 36, 329 (1957)

8. S. C. S Li, W. C. Huang, Computers \& Education, 96, 29-41. (2016)

9. D. Levinson, A. Boies, J. Cao, Y. Fan. The Transportation Futures Project: Planning for Technology Change (2016)

10. J. J. Yun, D. Won, E. Jeong, K. Park, J. Yang, J. Park, Technological Forecasting and Social Change, 103, 142-155 (2016)

11. F. Schragn, Journal of Philosophy of Education, 47, 20-30 (2013) 